\title{
Recycling and refining of copper for electrical application
}

\author{
Sébastien Dablement \\ Nexans Research Centre Lens, France
}

\begin{abstract}
Copper is, after silver, the best electrical conductor. All residual impurities inside the matrix have high consequences on these properties. Thus, the Nexans factory in Lens "purifies" the copper scraps by a fire refining in order to remove all the internal pollutant. This process, unique in France, is complementary to a traditional process using an electrolytic cathode. It allows, first, to diversify the raw material and, second, to increase the ecological balance compare to the traditional way of scrap treatment for electrical application.
\end{abstract}

\section{INTRODUCTION}

The copper conductors are traditionally made from electrolytic cathode coming from mainly South America but also from East of Europe and Africa.

The high worldwide needs of this raw material generate speculation and high fluctuation of the price. In order to diversify the sources, Nexans invested in a process to treat copper scraps in addition of a traditional melting process.

\section{TRADITIONAL MELTING PROCESS}

Electrolytic cathodes are melted in a vertical gas furnace. When the copper is liquid, it is transfer to a tempo furnace in order to, first, ensure the continuity of the process with a constant flow $(30 \mathrm{~T} / \mathrm{h})$ and, second, to allow to temporize the metal introduction in the casting process when there are some problems.

Then, this liquid metal is injected inside a casting wheel with a trapezoidal shape (section of 7 square inch) closed by a steel belt. Both wheel and belt are cooled by water in order to solidify the copper bar.

The solid bar goes out the wheel at about $900^{\circ} \mathrm{C}$ and goes to the rolling mill where a deformation is done in order to have a wire of $8 \mathrm{~mm}$ diameter.

Next, this wire is package on 5 tons coil and will sent in other factories of Nexans in order to be draw at smaller diameter.

\section{COPPER SCRAPS TREATMENT}

The scrap refining process of Nexans is based on the pollutant oxydation. For that, 5 additional furnaces had been installed in parallel to the classical melting process.

First, the scraps are melted in two furnaces, gas or induction according to the scrap. Then, after melting, the metal is transferred in two treatment furnaces where a first chemical analyze is done in order to define precisely the treatment to do. This treatment is composed of different steps. First, an oxidation with eventually some flux is done before skimming dross. These steps were repeated up to having a good chemical composition (compatible with an electrical application). Then, the melted copper is treated with hydrogen in order to remove the residual oxygen.

\begin{tabular}{|c|c|c|}
\hline & $\begin{array}{c}\text { Résistivité } \\
(\Omega . \mathrm{m})\end{array}$ & $\begin{array}{c}\text { Conductivité } \\
(\% \text { IACS })\end{array}$ \\
\hline Argent & $1.63 .10^{-8}$ & $106.1 \%$ \\
\hline Cuivre & $1.72 .10^{-8}$ & $100 \%$ \\
\hline Aluminium & $2.75 .10^{-8}$ & $62.7 \%$ \\
\hline Magnésium & $4.6 .10^{-8}$ & $37.5 \%$ \\
\hline Bronze & $5.5 .10^{-8}$ & $31.3 \%$ \\
\hline Zinc & $6.10^{-8}$ & $28.7 \%$ \\
\hline Nickel & $7.10^{-8}$ & $24.6 \%$ \\
\hline Laiton & $7.10^{-8}$ & $24.6 \%$ \\
\hline
\end{tabular}

Figure 1. Electrical conductivity of different materials.

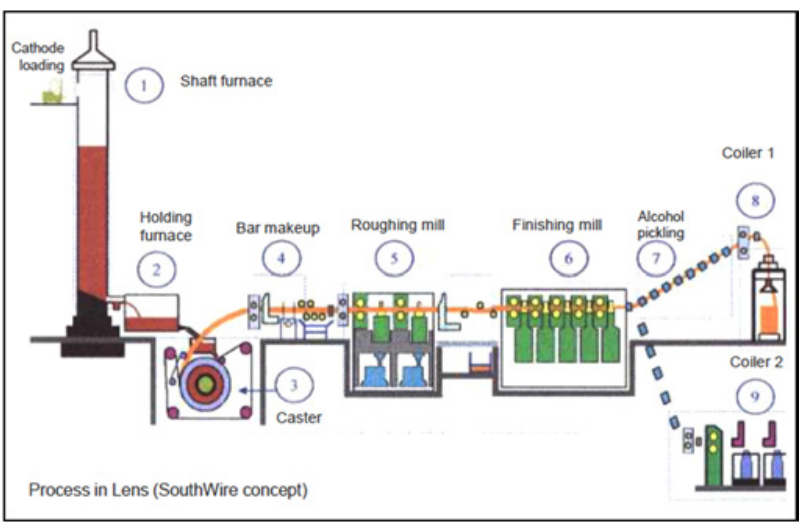

Figure 2. Copper melting process from electrolytic cathodes.

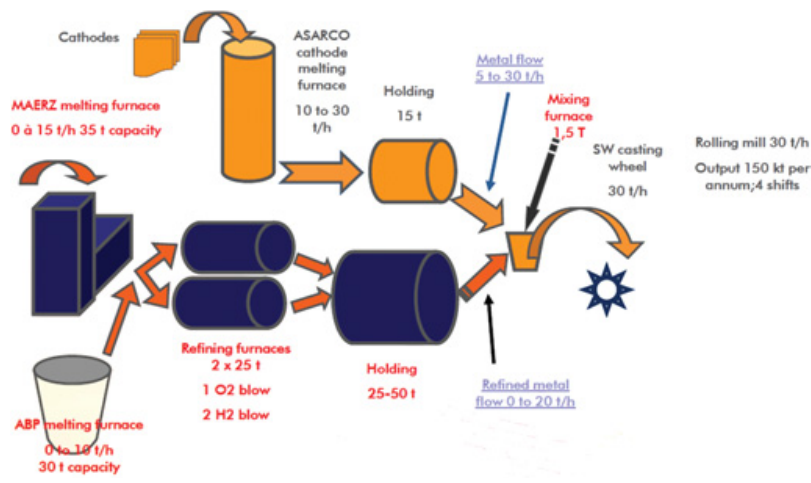

Figure 3. Integration of a copper scrap refining process.

After refining, the copper is transferred in an holding furnace in order to assure the continuity of the process and assure a constant flow. The refining metal is injected in the 
traditional melting process from electrolytic cathode. The ratio between the two copper sources is the order of $40 \%$ of scraps and $60 \%$ of electrolytic cathode.

\section{ECOLOGICAL AND ECONOMIC ASPECT}

The traditional process of copper scrap treatment for electrical application consists in doing a rough fire refining before casting anodes. The fine refining is done by the electrolyze of the anodes. A second fusion is necessary in order to produce wires.

Thus, the Nexans process saves both, one fusion and one electrolyze who consume a lot of energy.

On the economical point of view, the usage of copper scrap needs more furnaces and people compare the traditional melting process. However, this over cost is compensated by a low copper scrap price. 